\title{
Influência da expansão por umidade no comportamento mecânico de argilas para uso em blocos de cerâmica vermelha - revisão
}

\section{(Influence of moisture expansion on the mechanical behavior of structural clay materials for use in ceramic bricks - review)}

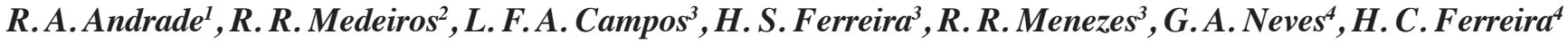 \\ ${ }^{I}$ Departamento de Engenharia Civil, Instituto Federal de Educação Tecnológica de Pernambuco, Recife, PE \\ ${ }^{2}$ Departamento de Engenharia Civil, Universidade Federal de Roraima, Amapa, AP \\ ${ }^{3}$ Departamento de Engenharia de Materiais, Universidade Federal da Paraíba, Cidade Universitária, J. Pessoa, PB \\ ${ }^{4}$ Unidade Acadêmica de Engenharia de Materiais, Universidade Federal de Campina Grande, Campina Grande, PB \\ romualdomenezes@pq.cnpq.br,liszandra@hotmail.com,gelmires@dema.ufcg.edu.br,heber@dema.ufcg.edu.br
}

\begin{abstract}
Resumo
O fenômeno da expansão por umidade (EPU) resulta da ação da água e seus vapores causando a expansão dos materiais cerâmicos, podendo provocar danos no material e prejudicar sua vida útil. Na literatura existe muita ênfase nos problemas gerados pela EPU e nas tensões resultantes dessa expansão, porém até o presente não há dados relativos ao comportamento mecânico dos materiais cerâmicos após ação da EPU. Trabalhos recentemente desenvolvidos na UFCG tratam especificamente desse problema em blocos cerâmicos de vedação. Inicialmente verificou-se que, no caso de massas cerâmicas para uso em cerâmica vermelha queimadas em diversas temperaturas na faixa de 700 a $1100{ }^{\circ} \mathrm{C}$, e com a EPU induzida por imersão, fervura e autoclavagem, a EPU tem correlação com o comportamento mecânico dos corpos queimados, observando-se redução no módulo de ruptura à flexão à medida que a EPU aumenta. Trabalhos desenvolvidos com massas para uso em cerâmica vermelha aditivadas com carbonato de cálcio e carbonato de magnésio e queimadas entre 850 e $1000{ }^{\circ} \mathrm{C}$, evidenciaram o efeito benéfico do carbonato de cálcio na redução da EPU e aumento da resistência à flexão, sendo observada correlação entre EPU e módulo de ruptura à flexão, mas, no entanto, não foi observada correlação entre a EPU e o módulo quando da utilização do carbonato de magnésio. Pesquisas efetuadas com massas para cerâmica vermelha aditivadas com quartzo fino, visando o desenvolvimento de fases vítreas, não mostraram correlações bem definidas entre EPU e módulo de ruptura, sendo observado que adições de 10 e $20 \%$ de quartzo melhoram a resistência mecânica dos corpos cerâmicos após autoclavagem e que a adição de $30 \%$ de quartzo reduz seu módulo de ruptura.
\end{abstract}

Palavras-chave: EPU, cerâmica vermelha, módulo de ruptura.

\begin{abstract}
Moisture expansion (ME) phenomenon results from the action of water and water vapors causing the expansion of ceramic materials, which may damage the material damage and jeopardize its useful life. In literature there is much emphasis on problems generated by the ME and the tensions resulting from this expansion, but until now there is a lack of data on mechanical behavior of ceramics after ME. Recent works in UFCG specifically deal with this problem in ceramic bricks. Initially it was found that in the case of ceramic bodies for use in red ceramic burned at different temperatures, ranging from 700 to $1100{ }^{\circ} \mathrm{C}$ with $\mathrm{ME}$ induced by soaking, boiling and autoclaving, the ME correlated with the mechanical behavior of burned bodies, and a reduction in modulus of rupture with the rising of $M E$ was observed. Researches undertaken with compositions developed using clay and calcium carbonate and magnesium carbonate as adds for red ceramic, burned from 850 to $1000{ }^{\circ} \mathrm{C}$, showed the beneficial effect of calcium carbonate in reducing moisture expansion and rise modulus of rupture. Correlations between ME and modulus of rupture, was observed when calcium carbonate was used as additive. However, this associations was noted when magnesium carbonate was used as additive. Works carried out using fine quartz as additive of red ceramic compositions and aiming glassy phases development not observed well defined correlations between ME and modulus of rupture. The addition of 10 and $20 \%$ of fine quartz improve the mechanical strength of ceramic bodies after autoclaving and that the addition of $30 \%$ of quartz decreases its mechanical strength.
\end{abstract}

Keywords: moisture expansion, red ceramic, modulus of rupture.

\section{INTRODUÇÃO}

A expansão por umidade (EPU) é o termo técnico utilizado para designar a expansão sofrida por materiais cerâmicos quando em contato com a água na forma líquida ou de vapor. Essa expansão geralmente ocorre lentamente e é relativamente pequena. Mesmo assim, pode levar ao gretamento de peças esmaltadas e ao comprometimento estrutural dos corpos cerâmicos caso as tensões geradas pela deformação contida das peças excedam os limites de 
resistência dos materiais [1,2]. As primeiras evidências da EPU foram reportadas por Merrit e Peters [3] já na década de 20 do século passado, tendo atraído a atenção de vários pesquisadores e cientistas, notadamente na África do Sul, Austrália, certos países da Europa e Estados Unidos [4, 5]. $\mathrm{O}$ grande interesse nesse fenômeno deveu-se a constatação que, junto com o ataque de sais a EPU é a causa mais comum de deterioração de tijolos, telhas e placas cerâmicas de revestimento em todo o mundo [2].

No Brasil também se observou manifestações de falhas de peças cerâmicas relacionadas ao fenômeno da EPU, com estudos $[2,6]$ relatando principalmente gretamentos, destacamentos e quebras de revestimentos cerâmicos por conseqüência da EPU. No entanto, no final do século passado verificou-se [7] que a EPU poderia estar associada a falhas estruturais de alvenarias no nordeste do país e desabamento de prédios na Grande Recife, PE. Nos últimos vinte e cinco anos na região metropolitana de Recife, PE, iniciou-se a construção de edifícios de alvenaria com blocos cerâmicos de vedação com quatro pavimentos. Geralmente esses edifícios são construídos em áreas planas, algumas delas alagáveis e com lençol freático muito elevado mesmo nos períodos de verão (estação seca). Há evidências de que blocos cerâmicos de vedação foram também utilizados, de forma indevida, nas fundações. Durante a vida útil desses edifícios, os blocos cerâmicos das fundações e do primeiro pavimento sofreram a ação constante das águas do lençol freático, o que aliada a uma deficiente drenagem, propiciou o surgimento da EPU, contribuindo para ocorrência de sérios problemas construtivos e ruína de vários edifícios [7]. Hoje se sabe que há um comprometimento estrutural de cerca de três mil edifícios na Grande Recife. Por solicitação da Defesa Civil do estado de Pernambuco e por iniciativa da Unidade Acadêmica de Engenharia de Materiais da Universidade Federal de Campina Grande, desde 1999 tem sido realizados estudos [7-12] com o objetivo de analisar as causas da falência estrutural de diversos edifícios e os resultados apontam a EPU como um dos fatores responsáveis pelo colapso estrutural, o que evidencia a grande importância do conhecimento da existência de correlações, ou não, entre a resistência dos corpos cerâmicos e o desenvolvimento de EPU. Nesse sentido, recentemente foram efetuadas amplas revisões de diversos aspectos relativos à EPU; no entanto, não foram observados dados relativos à influência da EPU no comportamento mecânico de materiais cerâmicos [2, 13]. A partir dos fenômenos da EPU pode-se prever que a hidratação dos silicatos anidros e do material amorfo e as conseqüentes expansões com a introdução de microtrincas e a diminuição de tensões de compressão existentes no material (em virtude da expansão) possam ocasionar uma redução da sua resistência mecânica. Foram efetuados estudos sobre EPU de corpos cerâmicos de cerâmica estrutural (cerâmica vermelha) induzida de diferentes formas, com graus de intensidade significativamente distintos, observando a influência da EPU no comportamento mecânico dos corpos estudados [10-12]. Foi evidenciado que quanto mais severo o método de indução da EPU maior a redução da resistência mecânica à flexão.

Os blocos e telhas cerâmicos confeccionados com massas cerâmicas constituídas predominantemente por argilas cauliníticas e ilíticas ricas em ferro são geralmente queimados em temperaturas de 800 a $1000{ }^{\circ} \mathrm{C}$, observandose uma grande quantidade de queimas em temperaturas em $\sim 900{ }^{\circ} \mathrm{C}$. No entanto, em argilas cauliníticas foi verificado um decréscimo da EPU à medida que a temperatura de queima aumentava, chegando a um mínimo em $\sim 850{ }^{\circ} \mathrm{C}$ e a seguir um aumento até atingir um máximo entre 900 e $950{ }^{\circ} \mathrm{C}$ [14]. Após esta faixa de temperatura a EPU volta a diminuir com a elevação da temperatura. Assim, observa-se que os blocos e telha cerâmicos são em geral queimados em temperaturas que, infelizmente, conduzem esses produtos a apresentarem uma elevada tendência para o desenvolvimento da EPU. Visando contornar esse problema foram conduzidas pesquisas aditivando massas cerâmicas para cerâmica estrutural com carbonato de cálcio, hidroxicarbonato de magnésio e quartzo (granulometria inferior a $74 \mu \mathrm{m}$ ) com objetivo de desenvolver fases cerâmicas e microestruturas mais estáveis à ação da EPU e reduzir fases propícias ao desenvolvimento de EPU $[11,12]$. Em seguida esses autores avaliaram a influência dos aditivos utilizados no comportamento dos corpos cerâmicos para analisar a correlação entre a EPU e sua resistência mecânica.

Este trabalho tem por objetivo efetuar uma revisão das ultimas pesquisas realizados na Unidade Acadêmica de Engenharia de Materiais da Universidade Federal de Campina Grande, relativos à EPU de corpos cerâmicos obtidos com massas para uso em cerâmica vermelha não aditivadas e aditivadas com carbonato de cálcio, hidroxicarbonato de magnésio e quartzo fino, que visaram avaliar a inter-relação entre EPU e comportamento mecânico [11, 12].

\section{PROPRIEDADES MECÂNICAS E A EPU DE BLOCOS CERÂMICOS}

A Fig. 1 apresenta os resultados para a EPU (\%) [10] obtidos por dilatometria de corpos-de-prova confeccionados por extrusão de massas de cerâmicas vermelhas industriais do estado da Paraíba, denominadas massas B, E e M. Os corpos-de-prova apresentavam dimensões $50 \mathrm{~mm}$ x $5 \mathrm{~mm}$ x $5 \mathrm{~mm}$ e foram queimados a $700,800,900,1000$ e $1100{ }^{\circ} \mathrm{C}$, e submetidos aos ensaios de indução de EPU nas condições a seguir: imersão em água destilada durante 30,60 e 90 dias; fervura por períodos de 8,10 e $24 \mathrm{~h}$ e autoclavagem utilizando uma pressão de $0,7 \mathrm{MPa}$ e temperatura de $160{ }^{\circ} \mathrm{C}$, por períodos de 2,4 e $5 \mathrm{~h}$. Pode-se observar em todas as curvas que a EPU comportou-se como indicado $[2,14,15]$, decréscimo, seguido por um máximo e novo decréscimo com o aumento da temperatura de queima, independentemente da condição de indução utilizada. Verifica-se também que quanto maior a severidade do ensaio de indução, maior a EPU medida. Verifica-se que o máximo de EPU ocorreu em $\sim 900{ }^{\circ} \mathrm{C}$ em todas as massas 

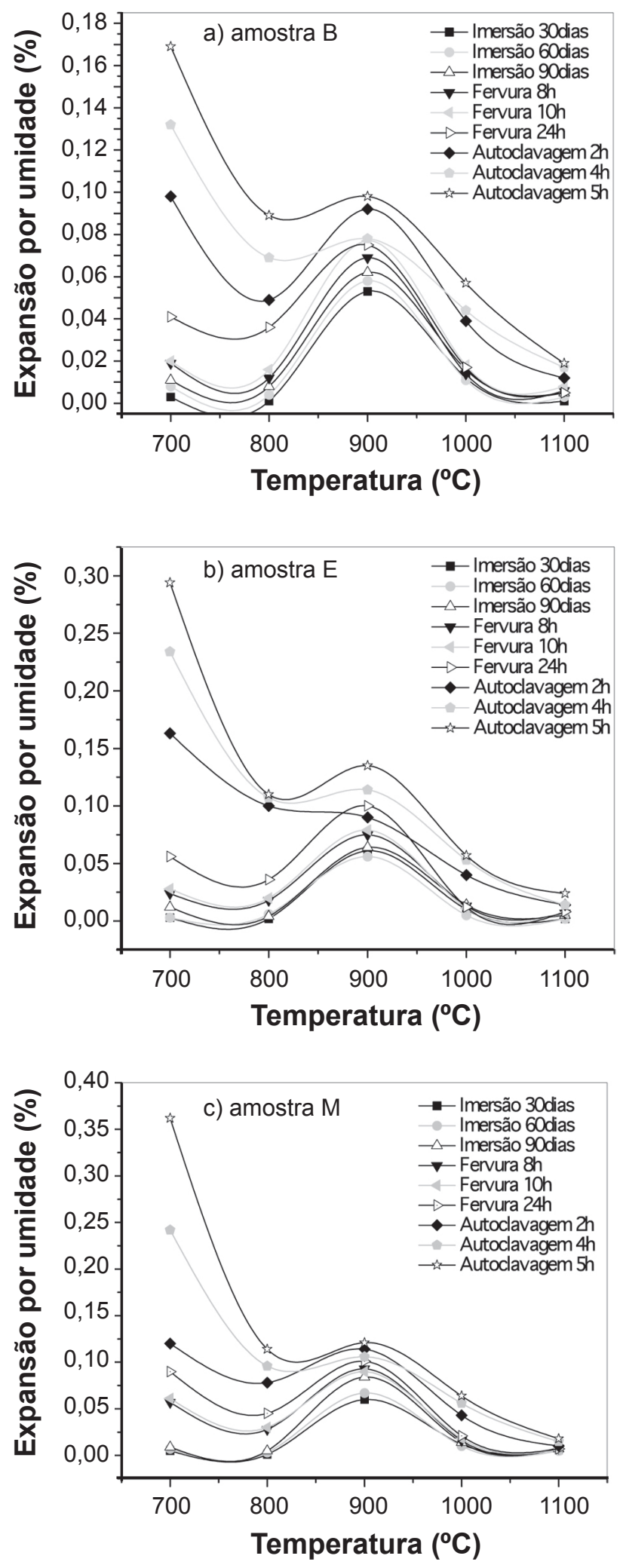

Figura 1: EPUs da a) amostra B, b) amostra E e c) amostra M, determinadas por dilatometria, em função da temperatura de queima, após ensaios de EPU por imersão, fervura e autoclave [10]. [Figure 1: Moisture expansion of a) sample B, b) sample E, sample $M$ determined by dilatometric measurements, as a functions of firing temperature, after moisture expansion tests of soaking, boiling and autoclaving [10].] (cauliníticas), independentemente do ensaio de indução utilizado, o que está associado ao mecanismo de destruição da caulinita e formação de fases amorfas com o aquecimento [16], o que é um fator preocupante, já que a maioria das indústrias de cerâmica vermelha utiliza esta temperatura para queima, ou valores próximos, causando assim um sério risco às construções com alvenarias cujas condições de uso favoreçam e/ou potencializem o desenvolvimento da EPU, tal como mencionado anteriormente.

Os ensaios de imersão em água e de fervura evidenciam uma baixa reatividade entre a água e as fases existentes nos corpos-de-prova queimados a 700 e $800{ }^{\circ} \mathrm{C}$, ao contrário dos ensaios em autoclave que são bem mais severos. Nas demais temperaturas observa-se que a reatividade das fases com relação a água depende menos do tipo de ensaio de indução utilizado, no entanto, a autoclavagem ainda provoca as maiores EPUs. Os valores observados na Fig. 1 são significativamente superiores ao indicado como elevado (superior $0,03 \%$ ) pela normalização australiana [17] para blocos cerâmicos. O que evidencia que as materiais-primas e as condições de processamento mais utilizadas no país potencializam o desenvolvimento de corpos com suscetibilidade para o desenvolvimento de elevadíssimas EPUs.

A Fig. 2 apresenta os resultados dos ensaios de resistência a flexão em três pontos dos corpos-de-prova queimados a $700,800,900$ e $1000{ }^{\circ} \mathrm{C}$. Os corpos foram confeccionados por extrusão com dimensões $150 \mathrm{~mm}$ x 20 $\mathrm{mm} \times 10 \mathrm{~mm}$. A velocidade de deslocamento do apoio de aplicação da carga foi $0,5 \mathrm{~mm} / \mathrm{min}$. Os corpos-de-prova queimados a $1100{ }^{\circ} \mathrm{C}$ apresentaram superqueima, com deformações nas arestas em virtude da pirodeformação, não sendo assim determinada a resistência dos corpos queimados nessa temperatura. Nos gráficos apresentados na Fig. 2 os valores do módulo de ruptura à flexão dos corpos-de-prova antes dos ensaios de EPU estão representados pela letra $\mathrm{A}$, os resultados após os ensaios de EPU estão representados de acordo com a descrição de cada condição de ensaio especificada: I30, I60 e T90 referem-se a imersão em água por 30,60 e 90 dias, respectivamente; F8, F10 e F24 referem-se a fervura por 8,10 e $24 \mathrm{~h}$, respectivamente e as denominações A2, A4 e A5 referem-se a autoclavagem a $0,7 \mathrm{MPa}$ e temperatura de $160{ }^{\circ} \mathrm{C}$ por 2,4 e $5 \mathrm{~h}$, respectivamente.

Com base na Fig. 2 observa-se, de forma geral, um decréscimo da resistência com o aumento da severidade do ensaio de indução de EPU, o que, juntamente com a Fig. 1, indica uma diminuição do módulo com o aumento da EPU. No entanto, esse comportamento apresenta singularidades, por exemplo, na amostra $M$ não se observam variações significativas nos módulos de ruptura dos corpos queimados a $900{ }^{\circ} \mathrm{C}$ com o aumento da severidade do ensaio até se realizar a autoclavagem por $5 \mathrm{~h}$. Por outro lado, nos corpos-de-prova da amostra $\mathrm{E}$ queimados por $900{ }^{\circ} \mathrm{C}$ verifica-se um decréscimo continuado do módulo conforme se eleva a magnitude de severidade do ensaio. Já nos corpos da amostra B queimados a $900{ }^{\circ} \mathrm{C}$ verifica- 

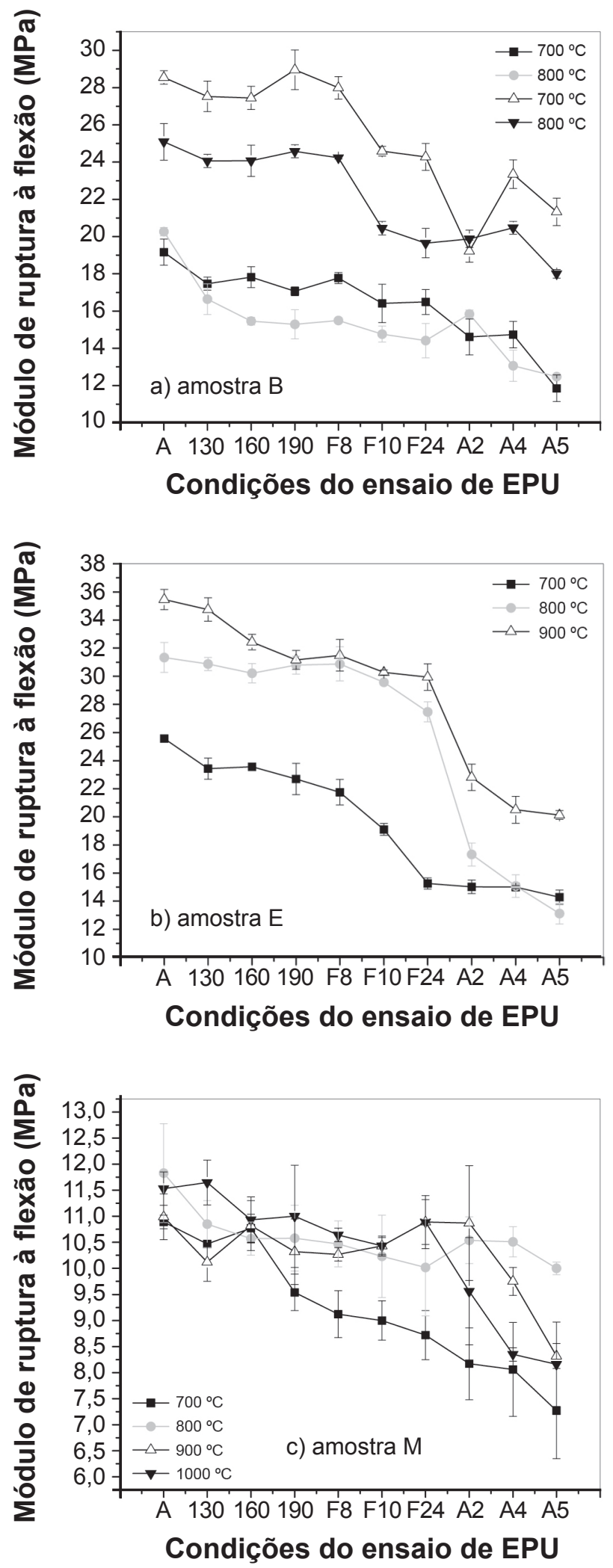

Figura 2: Módulo de ruptura à flexão das amostras B, E e M, determinadas pelo métodos dos três pontos, antes e após ensaios de EPU nas condições especificadas [10].

[Figure 2: Modulus of rupture of samples B, $E$ and $M$ before and after moisture expansion test, determined by the three points methodology [10].] se que só há um decréscimo significativo do módulo após o material ser submetido ao ensaio de fervura. Essas observações indicam que o comportamento do módulo de ruptura frente a EPU depende do material analisado e, por conseguinte, provavelmente, da sua composição mineralógica e características microestruturais após queima. A fim de analisar melhor o comportamento observado, foram realizados ensaios de caracterização microestrutural nos corpos estudados, observando o seguinte: a) os dados de difração de raios $\mathrm{X}$ não indicaram modificações na microestrutura cristalina das amostras; b) nas análises de espectroscopia de infravermelho não foram observadas alterações de intensidades nos picos e bandas de absorção relativos a água adsorvida, hidroxilas e ligações R-OH; c) os estudos por porosimetria de mercúrio e da área especifica dos sólidos pela metodologia de BET não apresentaram correlação com os valores de EPU determinados. Nesse trabalho, a ausência de correlações foi justificada pelo pequeno número de amostras estudadas, havendo uma recomendação para sua ampliação [10].

Nesse sentido, ao estudar a EPU de revestimentos cerâmicos induzida por fervura foi observada a lixiviação e corrosão do material durante o ensaio devido às correntes de convecção presentes durante o processo de fervura [8], o que indicou que a fervura poderia conduzir a um aumento da porosidade dos corpos-de-prova analisados [10], particularmente por se tratarem de materiais para blocos e telhas cerâmicos queimados em baixas temperaturas (comparativamente aos revestimentos analisados [8]). A Tabela I apresenta os dados [10] para a porosidade, obtida por porosimetria de mercúrio, e a área específica, obtida pela metodologia de BET, das suas amostras. Pode-se observar, que conforme ressaltado anteriormente [10], não se observa correlação entre o ensaio de aceleração e aumentos de porosidade no material. Não sendo possível correlacionar a diminuição de resistência mecânica nos corpos-de-prova após ensaio de EPU a aumentos de porosidade no material provocados pela corrosão da fase vítrea ou lixiviação da estrutura.

Vaughan e Dinsdale [18] afirmaram que o aumento da EPU ocasionará um aumento no diâmetro médio dos poros, devido às forças de expansão provocadas pela água adsorvida e a corrosão da fase vítrea pela água, abrindo poros fechados, o que vem ao encontro das observações de corrosão [8]. Por outro lado, foi evidenciado que uma das maiores dificuldades em comparar a EPU de corpos cerâmicos com suas áreas específicas está em diferenciar entre a superfície interna que está associada a superfícies ativas e aquela que não está associada a superfícies ativas, dentro das condições de exposição, chegando a conclusão de que a melhor correspondência entre a EPU e a área específica é obtida para poros com diâmetros entre 0,77 a $0,2 \mu \mathrm{m}$ [19]. Assim, a não observação [10] de correlação entre o decréscimo de resistência e a variação de porosidade provocada pela EPU e seus ensaios de indução pode está associado a não análise de uma faixa de porosidade específica. 
Tabela I - Porosidade obtida por porosimetria de mercúrio e área específica dos corpos-de-prova das amostras B, E e M após queima a $900{ }^{\circ} \mathrm{C}[10]$.

[Table I - Porosity and specific surface area of test specimens of samples B, E and M after firing at $900{ }^{\circ} \mathrm{C}$ [10].]

\begin{tabular}{llcc}
\hline Amostra & \multicolumn{1}{c}{ Condição } & Porosidade $(\%)$ & Área Específica $\left(\mathrm{m}^{2} / \mathrm{g}\right)$ \\
\hline \multirow{3}{*}{ Amostra B } & Antes de ensaio de EPU & 25,10 & 1,91 \\
& Após fervura por 24 h & 20,51 & 1,35 \\
& Após autoclavagem por 5 h & 23,04 & 2,73 \\
& Antes de ensaio de EPU & 18,18 & 3,53 \\
\multirow{4}{*}{ Amostra E } & Após fervura por 24 h & 19,27 & 2,77 \\
& Após autoclavagem por 5 h & 21,10 & 2,00 \\
& Antes de ensaio de EPU & 24,87 & 1,74 \\
\multirow{3}{*}{ Amostra M } & Após fervura por 24 h & 18,63 & 1,08 \\
& Após autoclavagem por 5 h & 24,37 & 1,56 \\
\hline
\end{tabular}

Interdependência entre as propriedades mecânicas e a EPU dos blocos cerâmicos com aditivação

Os primeiros trabalhos buscando correlacionar a EPU com a composição dos corpos cerâmicos observaram estreita correlação entre os aditivos utilizados e a EPU determinada, sendo enfatizado que a composição do corpo é, por vezes, mais importante que sua absorção de água (porosidade) quando se requer indicações do comportamento de EPU dos materiais cerâmicos [2]. Vários estudos [15, 20-26] vêm sendo desenvolvidos visando analisar a influência de aditivos na redução da EPU de corpos cerâmicos. No entanto, esses estudos detiveram-se basicamente na analise de corpos queimados acima de $1000{ }^{\circ} \mathrm{C}$, em geral, para revestimentos cerâmicos, e suas observações não podem ser aplicadas diretamente a blocos e telhas cerâmicos queimados em baixas temperaturas, como da ordem de $900{ }^{\circ} \mathrm{C}$. Para avaliar a influência da aditivação com carbonato de cálcio (PA) e hodroxicarbonato de magnésio (fonte de carbonato de magnésio com elevada pureza) (PA) na redução da EPU e sua conseqüente influência no comportamento mecânico foram utilizadas duas massas de cerâmicas usadas comercialmente para produção de blocos e telhas cerâmicos, denominadas, de Cerâmica A e Cerâmica B, provenientes do estado da Paraíba e Pernambuco, respectivamente [11]. Os corpos-deprova foram moldados por extrusão, nas dimensões $100 \mathrm{~mm}$ x $20 \mathrm{~mm}$ x $10 \mathrm{~mm}$ e queimados a $850,900,950$ e $1000{ }^{\circ} \mathrm{C}$. A EPU foi determinada por dilatometria após submeter os corpos-de-prova (50 $\mathrm{mm}$ x $5 \mathrm{~mm} \times 5 \mathrm{~mm}$ ) a autoclavagem a $1,2 \mathrm{MPa}$ a $180{ }^{\circ} \mathrm{C}$ por $5 \mathrm{~h}$. $\mathrm{O}$ módulo de ruptura à flexão foi determinado por ensaio de flexão em três pontos com velocidade de deslocamento do apoio de aplicação da carga de $0,5 \mathrm{~mm} / \mathrm{min}$.

A Fig. 3 apresenta o comportamento da EPU e o módulo de ruptura à flexão dos corpos cerâmicos contendo adições de carbonato de cálcio (12 e 18\% em massa) [11]. Há uma marcante redução da EPU com a adição do carbonato de cálcio e que ocorreu um concomitante aumento na resistência a flexão com a diminuição da EPU (adição de carbonato de cálcio) em ambas as massas analisadas. Foi observado por difração de raios $X$ o desenvolvimento de uma nova fase cristalina nos materiais aditivados com o carbonato após queima a $1000{ }^{\circ} \mathrm{C}$, a augita $\left(\mathrm{Ca}(\mathrm{Mg}, \mathrm{Fe}) \mathrm{Si}_{2} \mathrm{O}_{6}\right)$ [11]. Não foi feita difração de raios $\mathrm{X}$ nos corpos-de-prova queimados a 850,900 e $950{ }^{\circ} \mathrm{C}$, no entanto, frente a similar redução de EPU desses materiais. Foi também concluído que deveria ter também ocorrido a formação de fase cristalina nos corpos queimados a 850,900 e $950^{\circ} \mathrm{C}$.

Sabe-se que a adição de carbonato de cálcio propicia a formação de fases cristalinas em detrimento de fases vítreas e amorfas presentes no material [2,25]; no entanto, não havia sido observada na literatura a formação de fases cristalinas quando da adição de carbonato de cálcio em temperaturas de queima inferiores a $1000{ }^{\circ} \mathrm{C}$. Deve-se salientar que foi observado significativo aumento na porosidade dos corpos cerâmicos com da adição do carbonato de cálcio, particularmente nas maiores temperaturas de queimas. Por exemplo, a porosidade dos corpos aditivados com $18 \%$ de $\mathrm{CaCO}_{3}$ variou de 11 a $30 \%$; entretanto, não se observou aumento de EPU e sim, uma diminuição na EPU e elevação no módulo de ruptura [11], o que indica que a melhora na resistência pode estar relacionada à diminuição das fases vítreas e amorfas presentes no material e que, mesmo aumentando a porosidade total a presença de maior quantidade de fase cristalina propicia a elevação do módulo de ruptura. Vale salientar que foi observada nos corpos-deprova sem aditivação uma relação entre a EPU e o módulo de ruptura, antes e após autoclavagem, semelhante ao observado anteriormente [10]. A Tabela II apresenta os resultados obtidos [11], onde se observa que após autoclavagem há uma diminuição significativa da resistência da cerâmica A. Por outro lado, não foi observada variação significativa de resistência com a autoclavagem dos corpos da amostra cerâmica B, mesmo havendo significativo desenvolvimento de EPU. Estes resultados vêm ao encontro dos obtidos [10], que evidenciou que o modo de variação do comportamento mecânico com relação à EPU está intimamente relacionado à composição mineralógica e características microestruturais da amostra.

A Fig. 4 apresenta o comportamento da EPU e o módulo 

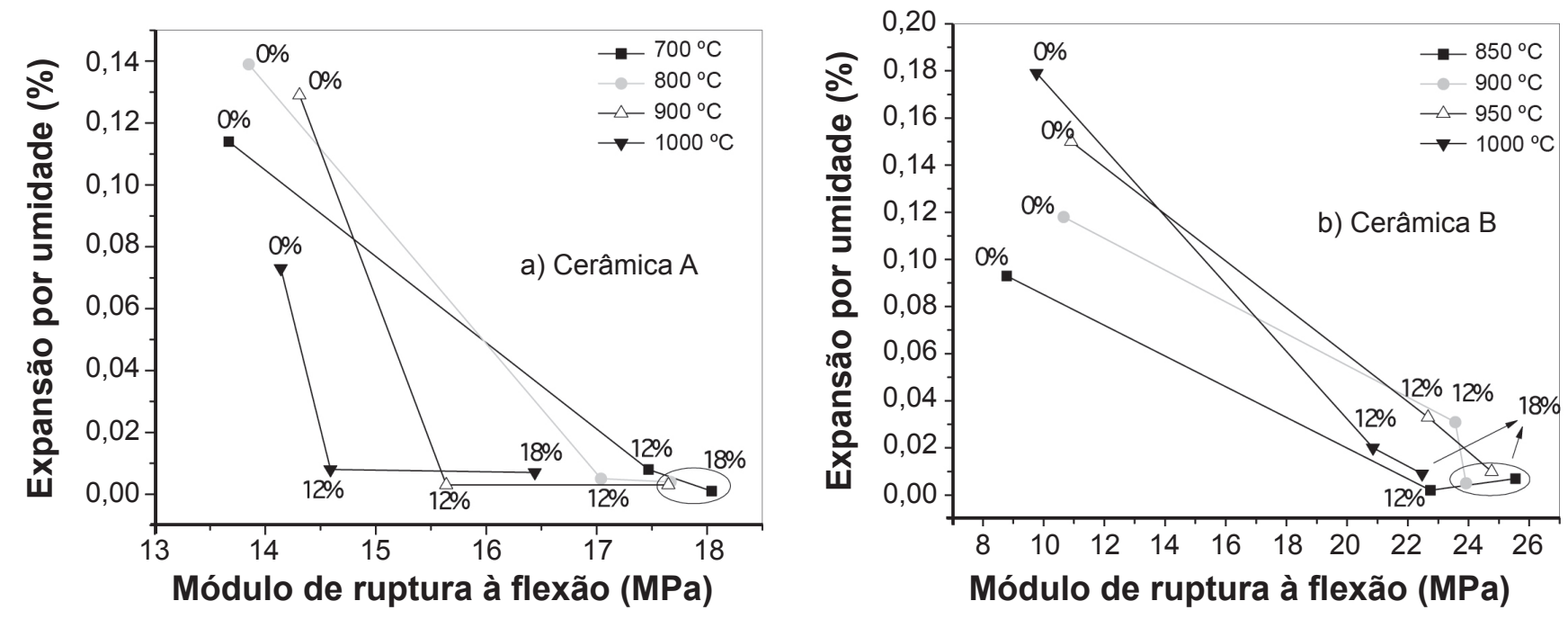

Figura 3: EPU versus módulo de ruptura à flexão de corpos cerâmicos autoclavados da a) cerâmica A e b) cerâmica B, com e sem adição de carbonato de cálcio (12 e 18\%) [11].

[Figure 3: Moisture expansion of modulus of rupture of autoclaved ceramic bodies of a) cerâmica A, b) cerâmica B, with and without calcium carbonate addition (12 and 18\%) [11].]

de ruptura à flexão dos corpos cerâmicos contendo adições de carbonato de magnésio (12 e 18\% em massa) [11]. Não há uma tendência bem definida, tal como observado quando da adição de carbonato de cálcio. Em algumas temperaturas de queima a adição do carbonato de magnésio propicia a redução da EPU. Por outro lado, em algumas outras temperaturas há um aumento da EPU. Foi concluído que não era possível definir algum tipo de correlação entre redução de EPU e aumento da resistência (ou vice-versa) com base nos dados obtidos, indicando ampliar o número de amostras para se obter um maior horizonte de análises [11]. Havia uma tendência do $\mathrm{MgO}$ (oriundo da decomposição do hidroxicarbonato de magnésio) permanecer na forma de $\mathrm{Mg}(\mathrm{OH})_{2}$, detectado por difração de raios X, após queima, o que poderia ter levado ao mascaramento e comprometimento das tendências e relação entre EPU e resistência à flexão. Sabe-se que $\mathrm{Mg}(\mathrm{OH})_{2}$ é expansivo e poderia aumentar a EPU determinada e comprometer a resistência mecânica dos corpos-de-prova com o desenvolvimento de trincas em virtude de sua ação expansiva. Estudos visando avaliar a influência do carbonato de magnésio na EPU de corpos cerâmicos $[25,26]$ também constataram a presença de $\mathrm{Mg}(\mathrm{OH})_{2}$ nos corpos queimados em temperatura de até $1200{ }^{\circ} \mathrm{C}$, reforçando, assim, os resultados [11]. Apesar da formação de brucita $\left(\mathrm{Mg}(\mathrm{OH})_{2}\right)$, foi observada por difração de raios $\mathrm{X}$ a formação de enstantita $\left(\mathrm{MgSiO}_{3}\right)$ e de silicatos de ferro e magnésio $\left((\mathrm{MgFe})_{2} \mathrm{SiO}_{4}\right)$ e de alumínio e magnésio $\left(\mathrm{Mg}_{2} \mathrm{Al}_{4} \mathrm{Si}_{5} \mathrm{O}_{18}\right)$ nas amostras aditivadas com hidroxicarbonato de magnésio após queima a $1000{ }^{\circ} \mathrm{C}$ [11], o que indica que, possivelmente, nesta temperatura de queima, pela menos parte das fases amorfas e/ou vítreas foram consumidas em detrimento da formação de novas fases cristalinas.

Visando avaliar a influência do empacotamento dos corpos-de-prova no desenvolvimento de EPU e comportamento da resistência frente as variações da EPU, foi

Tabela II - Expansão por umidade e módulo de ruptura das amostras cerâmica A e B antes e após autoclavagem [11]. [Table II - Moisture expansion and modulus of rupture of samples A and B, before and after autoclaving [11].]

\begin{tabular}{|c|c|c|c|c|c|}
\hline \multirow{2}{*}{ Amostras } & \multirow{2}{*}{$\begin{array}{c}\text { Temperatura } \\
\left({ }^{\circ} \mathrm{C}\right)\end{array}$} & \multicolumn{2}{|c|}{ Expansão por Umidade (\%) } & \multicolumn{2}{|c|}{ Módulo de Ruptura (MPa) } \\
\hline & & sem autoclavagem & autoclavada & sem autoclavagem & autoclavada \\
\hline \multirow{4}{*}{ Cerâmica A } & 850 & 0,013 & 0,114 & 23,99 & 13,67 \\
\hline & 900 & 0,050 & 0,139 & 21,93 & 13,85 \\
\hline & 950 & 0,030 & 0,129 & 26,00 & 14,31 \\
\hline & 1000 & 0,001 & 0,073 & 21,05 & 14,14 \\
\hline \multirow{4}{*}{ Cerâmica B } & 850 & 0,000 & 0,093 & 8,95 & 8,79 \\
\hline & 900 & 0,035 & 0,118 & 9,51 & 10,66 \\
\hline & 950 & 0,014 & 0,150 & 10,44 & 10,91 \\
\hline & 1000 & 0,025 & 0,179 & 9,76 & 9,77 \\
\hline
\end{tabular}


feita a aditivação de uma argila, utilizada comercialmente por indústria da Paraíba e do Rio Grande do Norte como a fração plástica de massas cerâmicas para a produção
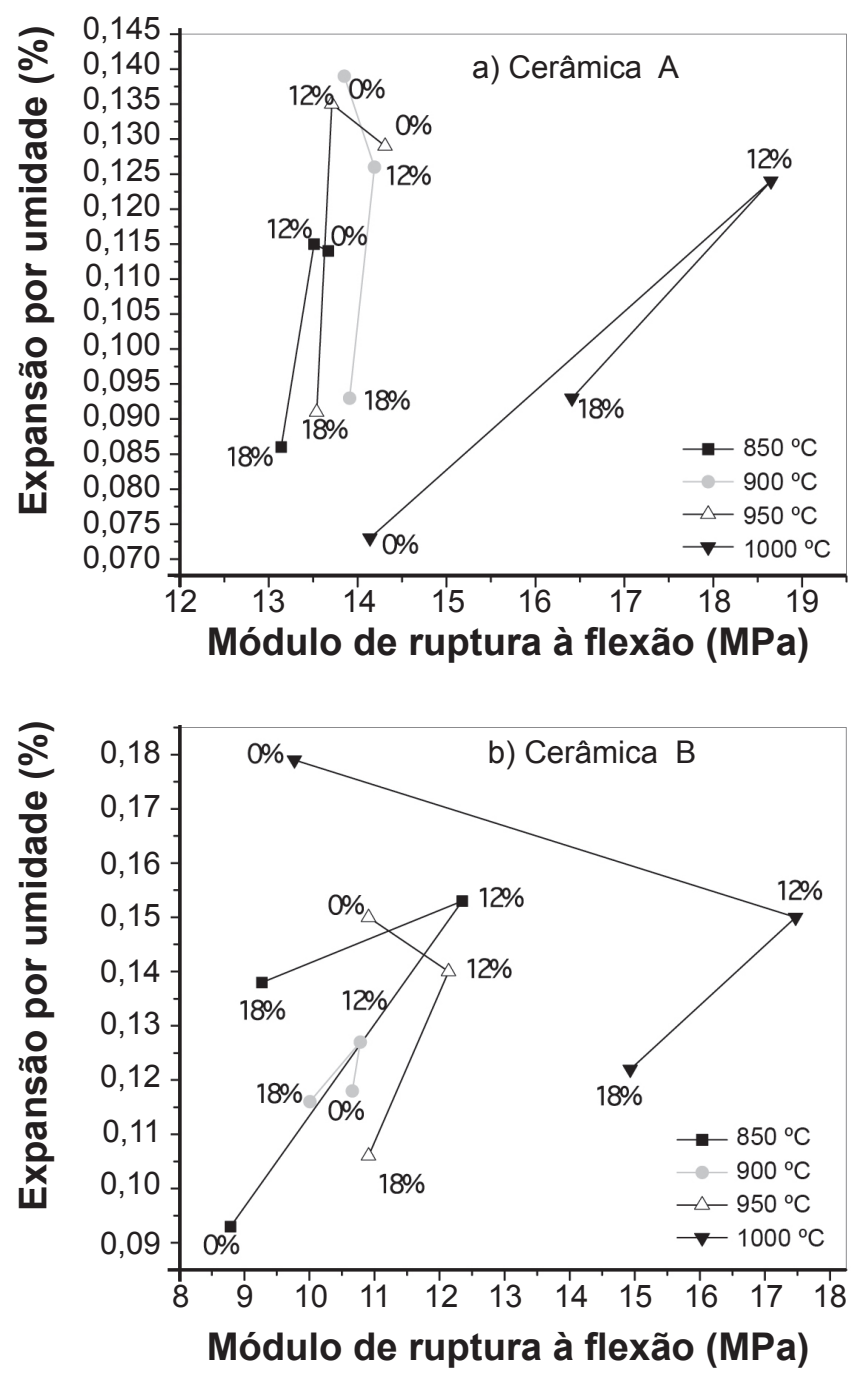

Figura 4: EPU versus módulo de ruptura à flexão de corpos cerâmicos autoclavados da a) Cerâmica A e b) Cerâmica B, com e sem adição de carbonato de magnésio (12 e 18\%) [11].

[Figure 4: Moisture expansion as a function of the flexure rupture modulus of the ceramic bodies. a) $A$ and $b$ ) $B$, with and without the addition of magnesium carbonate (12 e 18\%) [11].] de blocos e telhas cerâmica, com quartzo [12]. O quartzo foi utilizado nas proporções de 10, 20 e 30\% em massa e possuía granulometria inferior a $74 \mu \mathrm{m}$. Cole e Banks [27] evidenciaram que influências do quartzo na determinação da EPU (descolamento do quartzo da matriz vítrea) só são observadas em corpos de textura grosseira; desse modo, foi utilizado quartzo com elevada finura a fim de eliminar possíveis influências do quartzo, propriamente dito, na determinação da EPU, possibilitando analisar apenas a influência de alterações de empacotamento da massa (por adição do quartzo) na EPU e no módulo de ruptura dos corpos cerâmicos [12]. Os corpos cerâmicos foram produzidos por extrusão, sendo as dimensões dos corpos-de-prova, a determinação do módulo de ruptura, a forma de determinação da EPU (dilatometria) iguais aos utilizados [11]. No entanto as condições do ensaio de indução da EPU foram: pressão de autoclavagem $0,7 \mathrm{MPa}$, temperatura $160{ }^{\circ} \mathrm{C}$ e tempo $5 \mathrm{~h}$ A Fig. 5 apresenta os resultados para a EPU e o módulo de ruptura dos corpos-de-prova autoclavados [12].

$\mathrm{Na}$ Fig. 5 verifica-se que não há tendências bem definidas

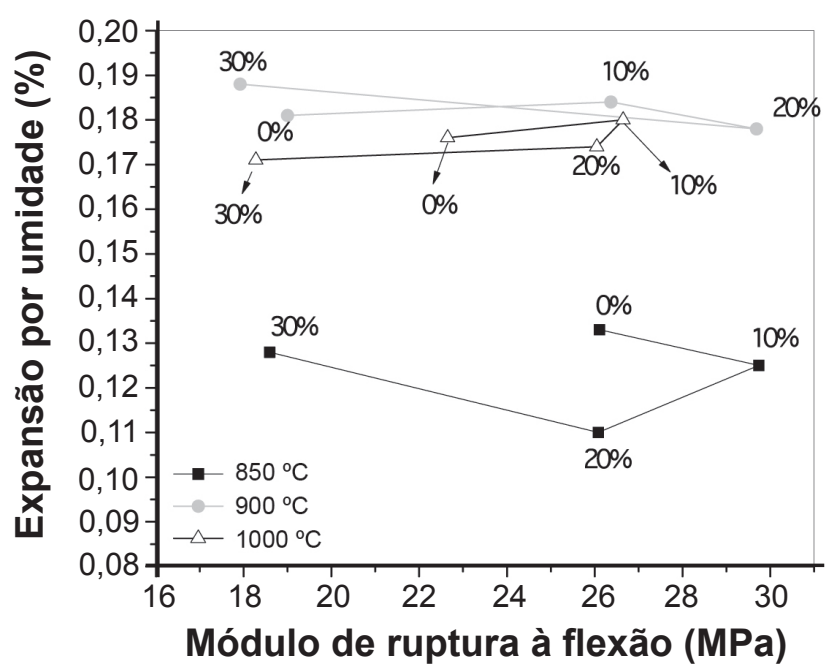

Figura 5: EPU versus módulo de ruptura à flexão de corpos cerâmicos autoclavados contendo adições de 0,10, 20 e 30\% de quartzo [12].

[Figure 5: Moisture expansion versus modulus of rupture of autoclaved ceramic bodies with 0, 10, 20 and 30\% of quartz [12].]

Tabela III - Porosidade aparente (determinada por imersão em água) de corpos cerâmicos antes e após o ensaio de autoclavagem para indução de EPU [12].

[Table III - Ceramic bodies apparent porosity (determined by water soaking) determined before and after autoclave test for moisture expansion induction [12].]

Porosidade Aparente $(\%)^{\mathrm{a}}$

\begin{tabular}{ccccccccc}
\cline { 2 - 8 } & \multicolumn{2}{c}{ Puro (0\%) } & \multicolumn{2}{c}{$10 \%$ Quartzo } & \multicolumn{2}{c}{$20 \%$ Quartzo } & \multicolumn{2}{c}{$30 \%$ Quartzo } \\
& Antes $^{\mathrm{a}}$ & Após $^{\mathrm{b}}$ & Antes $^{\mathrm{a}}$ & Após $^{\mathrm{b}}$ & Antes $^{\mathrm{a}}$ & Após $^{\mathrm{b}}$ & Antes $^{\mathrm{a}}$ & Após $^{\mathrm{b}}$ \\
\cline { 2 - 9 } $850{ }^{\circ} \mathrm{C}$ & $17,88 \pm 2,19$ & $18,71 \pm 0,87$ & $23,53 \pm 0,55$ & $23,91 \pm 0,86$ & $24,96 \pm 1,22$ & $24,42 \pm 1,28$ & $23,25 \pm 0,51$ & $24,20 \pm 0,75$ \\
$900{ }^{\circ} \mathrm{C}$ & $11,68 \pm 0,39$ & $15,87 \pm 0,78$ & $20,20 \pm 0,84$ & $20,61 \pm 0,64$ & $21,97 \pm 0,88$ & $24,49 \pm 1,70$ & $23,67 \pm 0,53$ & $25,18 \pm 0,83$ \\
$950{ }^{\circ} \mathrm{C}$ & $12,43 \pm 1,31$ & $16,58 \pm 0,82$ & $18,21 \pm 1,39$ & $19,09 \pm 0,69$ & $20,04 \pm 2,09$ & $22,42 \pm 0,85$ & $23,70 \pm 0,53$ & $25,05 \pm 1,35$ \\
\hline
\end{tabular}

antes do ensaio de autoclavagem: ${ }^{b}$ após o ensaio de autoclavagem 
entre a adição do quartzo e a EPU e entre alterações na EPU e modificações no módulo de ruptura. Observa-se que a adição de quartzo não provocou alterações significativas na EPU dos corpos queimados a 900 e $950{ }^{\circ} \mathrm{C}$. Os corpos que apresentaram maiores alterações de EPU com a adição de quartzo foram os queimados a $850{ }^{\circ} \mathrm{C}$, no entanto, essas variações ainda são significativamente inferiores às observadas [11] quando da aditivação dos corpos com carbonato de cálcio. Observa-se também, que o módulo de ruptura foi significativamente afetado pela adição de quartzo à massa, constatando-se elevações no módulo quando do uso de 10 e/ou $20 \%$ de quartzo, dependendo da temperatura de queima, e decréscimo no módulo quando a massa foi aditivada com $30 \%$ de quartzo. As adições de quartzo à massa cerâmica provocaram alterações de porosidade nos corpos queimados. A Tabela III apresenta os dados de porosidade aparente (determinada através de imersão em água por 24 h) determinados antes e após o ensaio de autoclavagem [12]. Ocorreu um aumento gradual da porosidade com a adição do quartzo em todas as temperaturas analisadas. No entanto, as amostras sem adição de quartzo foram as que apresentaram as maiores variações de porosidade após o ensaio de autoclavagem. Dados da literatura $[13,28$, 29] indicam que o ensaio de autoclavagem, por ser muito severo, provoca acentuada corrosão da fase vítrea e abertura de poros fechados existentes no material aumentando sua porosidade aparente, o que se faz acreditar que a variação de porosidade observada [12] com mais intensidade nas amostras sem adição de quartzo está relacionada a maior quantidade de fase vítrea nesses materiais (em virtude de sua maior fração argila).

Assim, a elevação do módulo de ruptura das amostras aditivadas com quartzo não pode estar relacionada a um aumento (melhora) de empacotamento do sistema, já que foi observado um nítido aumento de porosidade em todas as temperaturas [12]. Acredita-se que essa melhora na resistência dos corpos autoclavados com a aditivação do quartzo pode estar relacionada ao desenvolvimento de uma microestrutura que, apesar de ter uma maior porosidade aparente, possui uma maior resistência a corrosão do vapor de água superaquecido. Sabe-se que vidros com um menor teor de álcalis (maior teor de sílica) possuem uma maior resistência a corrosão e lixiviação; assim, acredita-se que mesmo formando-se menor quantidade de fase vítrea (menor fração argila) nas amostras aditivadas [12] essa fase vítrea é mais resistente a corrosão, o que resultaria em maior resistência do material aditivado após o ensaio de autoclavagem. Não se observa aumento do módulo de ruptura quando da utilização de $30 \%$ de quartzo porque o efeito de aumento da porosidade, nesse caso, já seria muito intenso e superaria qualquer efeito de melhora na resistência da fase vítrea presente no corpo cerâmico, provocando a diminuição de sua resistência. Vale salientar que foi observado um decréscimo da resistência dos corpos (sem aditivação) cerâmicos após o ensaio de autoclavagem [12], semelhante ao observado [10]. Não foi verificado o desenvolvimento de novas fases cristalinas (após análise de difração de raios X) nos materiais aditivados com quartzo, o que poderia justificar a melhora na resistência desses materiais tal como ocorrido quando da aditivação com carbonato de cálcio [11]. Acredita-se que a composição do corpo é mais importante que suas características de absorção de água e porosidade quando se requer indicações do comportamento de EPU dos materiais cerâmicos, sendo constatado [12] que alterações de empacotamento do corpo cerâmico (maiores porosidades) não podem ser associadas diretamente a maiores ou menores EPUs e/ou resistências após ensaio de indução de EPU.

\section{CONCLUSÕES}

Dados da literatura indicaram que há uma tendência decrescente da resistência mecânica dos corpos cerâmicos com o aumento da severidade dos ensaios de indução de EPU e, portanto, com o aumento da EPU; não se observaram alterações microestruturais relacionadas ao desenvolvimento de novas fases cristalinas, alteração de porosidade ou adsorção de água que explicassem por si só a inter-relação observada entre as EPUs e os módulos de ruptura à flexão dos corpos de cerâmica vermelha; a aditivação dos corpos cerâmicos com carbonato de cálcio provoca redução da EPU e aumento da resistência dos corpos mesmo quando de sua queima em temperaturas inferiores a $1000{ }^{\circ} \mathrm{C}$; não foi observada correlação evidente entre os valores de EPUs e dos módulos de ruptura dos corpos aditivados com carbonato de magnésio e com sílica; verificou-se um aumento da resistência após ensaio de autoclavagem dos corpos aditivados com teores de 10 e $20 \%$ de sílica, no entanto, sem correlação evidente com suas EPUs.

\section{REFERÊNCIAS}

[1] L. C. Chiari, C. J. A. Oliveira, C. S. Monteiro, N. V. Forjaz, A. O. Boschi, Ceram. Ind. 1, 1 (1996) 6.

[2] R. R. Menezes, L. F. Campos, G. A. Neves, H. C. Ferreira, Cerâmica 52 (2006) 1.

[3] G. E. Merritt, C. G. Peters, J. Am. Ceram. Soc. 9, 6 (1926) 327.

[4] R. Bowman, Ind. Ceram. 16, 2 (1996) 89.

[5] A. M. Segadães, M. A. Carvalho, H. C. Ferreira, Ceram. Int. 29, 8 (2003) 947.

[6] R. R. Menezes, L. F. Campos, H. S. Ferreira, H. C. Ferreira, Ceram. Ind. 10, 2 (2005) 27.

[7] ATECEL, Associação Técnico-Científica Ernesto Luiz de Oliveira Júnior, Rel. Técnico: "Causas do desabamento do bloco "B" do conjunto residencial Enseada de Serrambi, Olinda", UFPB, Campina Grande, PB (1999) p.15.

[8] R. R. Menezes, "Estudo da expansão por umidade e de características cerâmicas correlatas de placas cerâmicas para revestimentos", Diss. Mestrado, Coordenação de Pós-Graduação em Engenharia Química, UFCG, Campina Grande, PB (2001).

[9] F. S. Miranda, "Estudo da expansão por umidade e da resistência mecânica dos tijolos do edifício Aquarela, Jaboatão dos Guararapes”, Diss. Mestrado, Coordenação 
de Pós-Graduação em Engenharia Civil, UFCG, Campina Grande, PB (2001).

[10] L. F. A. Campos, "Estudo da Expansão por Umidade (EPU) em blocos cerâmicos do Estado da Paraíba", Diss. Mestrado, Coordenação de Pós-Graduação em Engenharia Química, UFCG, Campina Grande, PB (2002).

[11] R. A. Andrade, "Efeito da ação de carbonatos sobre a expansão por umidade associada às propriedades cerâmicas de blocos destinados à construção civil", Tese Dr., Coordenação de Pós-Graduação em Engenharia de Processo, UFCG, Campina Grande, PB (2009).

[12] R. R. Medeiros, "Influência do teor de quartzo na expansão por umidade e no comportamento mecânico de massas cerâmicas para uso em blocos furados", Tese Dr., Coordenação de Pós-Graduação em Engenharia de Processo, UFCG, Campina Grande, PB (2010).

[13] R. R. Menezes, L. F. Campos, G. A. Neves, H. C. Ferreira, Cerâmica 52 (2006) 114.

[14] J. E. Young, W. E. Brownell, J. Am. Ceram. Soc. 42, 12 (1959) 571

[15] A. A. Milne, Trans. Brit. Ceram. Soc. 57, 3 (1958) 148.

[16] P. Souza Santos, Ciência e Tecnologia de Argilas. $3^{a}$

Ed., Edgard Blücher, S. Paulo, SP (1992) p. 408.

[17] AS 1226.5, Australian Standard - "Methods of sampling and testing clay building bricks: Method for determining characteristic expansio" (1984).
[18] F. Vaughan, A. Dinsdale, Trans. Brit. Ceram. Soc. 61, 1 (1962) 1

[19] W. F. Cole, Nature 196, 4850 (1962) 127

[20] R. T. Laird, A. A. Wickens, Trans. Brit. Ceram. Soc. 67, 12 (1968) 629.

[21] G. C. Robinson, Am. Ceram. Soc. Bull. 64, 5 (1985) 712.

[22] R. G. Smith, Trans. Brit. Ceram. Soc. 92, 6 (1993) 233.

[23] B. E. Yekta, P. Alizadeh, Am. Ceram. Soc. Bull. 75, 5 (1996) 84.

[24]. L. C. Chiari, C. J. Oliveira, C. Monteiro, N. V. Forjaz, E. Biscaro, L. F. Marino, A. O. Boschi, Ceram. Ind. 1, 3 (1996) 35 .

[25] C. Lira, O. E. Alarcon, M. D. M. Silveira, J. A. A. Bianchi, E. L. Honorato, L. Costa, Ceram. Ind. 2, 1-2 (1997) 27.

[26] C. Lira, "Efeito de carbonatos de $\mathrm{Ca}, \mathrm{Mg}$ e $\mathrm{Li}$ e do ciclo de queima na expansão por umidade de materiais cerâmicos porosos para revestimento", Diss. Mestrado, UFSC, Florianópolis (1997).

[27] W. F. Cole, J. P. Banks, Key Eng. Mater. 53-55 (1991) 185.

[28] F. Vaughan, A. Dinsdale, Nature 183, 4661 (1959) 600. [29] R. Harrison, A. Disndale, Trans. Brit. Ceram. Soc. 63 (1964) 63.

(Rec. 06/04/2010, Ac. 28/08/2010) 